\title{
Bleeding Volume, Blood Pressure, and Consciousness Level in Association with the Mortality Rate among Patients with Intracerebral Hemorrhage at Dr. Soetomo General Hospital, Surabaya
}

\author{
Mohammad Pratama Jauhar Putra, ${ }^{1}$ Achmad Firdaus Sani, ${ }^{2}$ Puji Lestari, ${ }^{3}$ Mohammad Saiful Ardhi ${ }^{2}$ \\ ${ }^{1}$ Faculty of Medicine, Airlangga University, Surabaya, Indonesia, ${ }^{2}$ Department of Neurology, Dr. \\ Soetomo General Academic Hospital, Surabaya, Indonesia, ${ }^{3}$ Department of Public Health, \\ Faculty of Medicine, Airlangga University, Surabaya, Indonesia
}

\section{Abstract}

Background: Intracerebral hemorrhage is one of the deadliest acute conditions. The volume of bleeding and its location are factors that alter consciousness level, leading to death. This study aimed to explore the association between bleeding volume, blood pressure, and consciousness level with the mortality rate among patients with intracerebral hemorrhage, so proper treatment and diagnosis can be conducted efficiently.

Methods: This was an observational retrospective study conducted from October 2018-July 2019. Bleeding volume, blood pressure, consciousness level, and mortality as the outcomes of the patients with intracerebral hemorrhage were evaluated. Consciousness level was determined by using the Glasgow Coma Scale score. Data were collected from the medical record of intracerebral hemorrhage patients of the Neurologic Department in Dr. Soetomo General Academic Hospital Surabaya in the period of 2016. The Chi-square analysis method was used to determine the correlation between variables.

Results: In total, 51 medical records were retrieved, and the majority of the patients were in the 45-60 years old group (54.9\%). The mortality during hospitalization was $17.6 \%$ with most of them $(82.4 \%)$ had bleeding volume less than $30 \mathrm{cc}$. Interestingly, the bleeding volume correlated with the consciousness level $(p=0.001)$ and the outcome of the patients $(p=0.02)$. The blood pressure shows a correlation with the volume of bleeding $(\mathrm{p}=0.009)$.

Conclusions: Bleeding volume and consciousness level as determined by the Glasgow Coma Scale score show significant correlations with the mortality rate in patients with intracerebral hemorrhage.

Keywords: Intracerebral hemorrhage, mortality rate, volume of bleeding

\section{Introduction}

Intracerebral hemorrhage has been increased by $47 \%$ during the year 1990 to 2010 worldwide. In Indonesia, approximately over a million people are reported to have a stroke, and East Java is one of the big three provinces with the highest rate of stroke. ${ }^{1}$ Intracerebral hemorrhage is one of the deadly acute conditions, mostly occurred in the first 48 to 72 hours, caused by the neurological condition of the patients. ${ }^{2}$ The mortality rate in the first 30 days is $40 \%$ and this rate is increased by 10 $\%$ in 1 year.
Intracerebral hemorrhage is bleeding in the parenchymal brain tissue, ${ }^{3}$ leading to the deterioration of the patient. Not only the bleeding, but the location of the bleeding is one of the factors resulting in death. Computed Tomography (CT) scan is one of the radiological imaging that is commonly used to determine the degree of bleeding in intracerebral hemorrhage cases. During the CT scan, part of the brain where the hemorrhage has occurred presents as a white mass with a hypodense area in the surrounding area.

There are a lot of factors that can affect the clinical outcome of intracerebral hemorrhage

Correspondence: Mohammad Pratama Jauhar Putra, Faculty of Medicine, Airlangga University, Jalan Mayjen Prof. Dr. Moestopo No.47, Surabaya, East Java, Indonesia. E-mail: tommy_gkb@yahoo.co.id 
patients. This study aimed to explore the association between bleeding volume, blood pressure, and consciousness level with the mortality rate among patients with intracerebral hemorrhage. This study was needed to improve the clinical treatment and the diagnosis of intracerebral hemorrhage.

\section{Methods}

This was an analytic observational retrospective study, using medical record retrieved from the medical records centre in Dr. Soetomo General Hospital, Surabaya. Data were taken from the Department of Neurology in the period of January to December 2016.

The characteristic data of patients were collected such as gender and age. The age category was divided into three groups; young adult (18-45 years old), adult (45-60 years old), and old or geriatric patients ( $>60$ years old). Furthermore, data on blood pressure, bleeding volume, consciousness level, and outcomes of the patient were retrieved. Blood pressure was divided into four categories following the Joint National Committee 7; which were normal $(<120$ over $<80)$, elevated
(120-129 over 80-89), hypertension stage 1 (130-139 over 90-9) and hypertension stage 2 (>160 over $>100)$. Bleeding volume was divided into two categories; volume $<30$ $\mathrm{ml}$ and $>30 \mathrm{ml}$. The consciousness level was measured by the Glasgow Coma Scale (GCS) score, taken when they first admitted to the hospital. The Glasgow Coma Scale score was divided into three categories; severe $(<8$ points), moderate ( $8-12$ points) and mild ( $>12$ points). The bleeding volume was divided into two categories of $<30 \mathrm{cc}$, and $>30 \mathrm{cc}$.

The outcomes of the patients was categorized into two, alive when they were discharged from the hospital or death during the hospitalization. Only complete data were included. Exclusion criteria were patients diagnosed with subarachnoid hemorrhage or intraventricular hemorrhage, and when the location of the bleeding was infratentorial.

The Chi-square analysis method was used to assess the significant association between variables. The method of this study had been approved by the Ethical Committee of Dr. Soetomo General Hospital no. 0701/ KEPK/X/2018.

Table 1 Consciousness Level, Bleeding Volume, and Blood Pressure in Relation with the Outcomes among Patients with Intracerebral Hemorrhage at Dr. Soetomo General Hospital Surabaya

\begin{tabular}{lccc}
\hline & \multicolumn{2}{c}{ Outcome } & \multirow{2}{*}{ P-value } \\
\cline { 2 - 3 } & Death & Alive & \\
\hline Consciousness Level & 4 & 1 & \\
$<8$ & 4 & 20 & $0.0001^{*}$ \\
$8-12$ & 1 & 21 & \\
$>12$ & & & $0.02^{*}$ \\
Bleeding volume & 5 & 37 & \\
$<30$ cc & 4 & 5 & \\
$>30$ cc & & & \\
Blood Pressure & 1 & 1 & 0.597 \\
Normal & - & 1 & \\
Prehypertension & - & 1 & \\
Hypertension stage 1 & 8 & 39 & \\
Hypertension stage 2 & & & \\
\hline
\end{tabular}

Note: Consciousness level was determined by Glasgow Coma Scale Score; severe ( $<8$ points), moderate (8-12 points) and mild ( $>12$ points).* statistically significant. 
Mohammad Pratama Jauhar Putra et al.: Bleeding Volume, Blood Pressure, and Consciousness Level in Association with the Mortality Rate among Patients with Intracerebral Hemorrhage at Dr. Soetomo General Hospital, Surabaya

Table 2 Blood Pressure and Level of Consciousness in Relation with Bleeding Volume among Patients with Intracerebral Hemorrhage at Dr. Soetomo General Hospital Surabaya

\begin{tabular}{lccc}
\hline & \multicolumn{2}{c}{ Volume of bleeding } & P-value \\
\cline { 2 - 3 } & $<30$ cc & $>30$ cc & $0.009 *$ \\
Blood pressure & 1 & 1 & 1 \\
Normal & - & 1 \\
Prehypertension & - & 6 \\
Hypertension stage 1 & 41 & \\
Hypertension stage 2 & &
\end{tabular}

Note: ${ }^{*}$ statistically significant

\section{Results}

Of 117 medical records retrieved, only 51 data were considered eligible to be analyzed according to the exclusion and inclusion criteria. Male $(\mathrm{n}=29)$ was slightly more prevalent compared to females $(n=22)$ and the age of intracerebral hemorrhage patients was mostly in the adult group (54.9\%) with an average of 53.36 years old (data not shown).

The blood pressure among intracerebral hemorrhage patients was predominantly in the category of hypertension stage $2(n=47$; $92.2 \%)$. The percentage of the GCS was mild $(\mathrm{n}=22 ; 43.1 \%)$, moderate $(\mathrm{n}=24 ; 47.1 \%)$ and severe (n-5; 9.8\%) as shown in Table 1.

The bleeding volume category <30cc was detected in $82.4 \%(n=42)$ with a mean bleeding volume of $11.34 \mathrm{cc}$. For the category $>30 \mathrm{cc}$ there was $17.6 \%(\mathrm{n}=9))$ with a mean bleeding volume of $51.18 \mathrm{cc}$. The total patients who died during hospitalization were $17.6 \%$ (n9) and mostly were alive which was $82.4 \%$ $(\mathrm{n}=42)$.

There was a significant relationship between the outcome of the intracerebral hemorrhage and consciousness level (p0.0001) and bleeding volume ( $p$ 0.02) as shown in Table 1. Interestingly, even though there was a high number of hypertension stage 2 among patients, the bleeding volume was mostly $<30$ cc with p-value 0.009 as depicted in Table 2 . However, no significant difference between consciousness level and bleeding volume $(\mathrm{p}=0.339)$ nor blood pressure $(\mathrm{p}=0.329)$.

\section{Discussion}

This study has shown that the most prevalent age group with intracerebral hemorrhage is the adult group (45-60 years old) similar to another study however, some other studies also show that age older than 60 years old is more prevalent. ${ }^{4}$ The contradictory result of this study may correlate with the condition in Indonesia. In Indonesia ${ }^{1}$, the highest number of smokers belongs to the adult group. Since smoking is one of the risk factors of intracerebral hemorrhage, it may be the reason why most of the intracerebral hemorrhage patients are into an adult group in this study. ${ }^{1}$

High blood pressure is one of the most common risk factors in intracerebral hemorrhage. The high blood pressure would make blood vessels in the brain ruptured and bleeding occurs. Among the four categories, most of the patients (38 of 51) are in the hypertension stage 2 group. This result is similar to another study, showing that the mean initial systolic of the intracerebral hemorrhage patient is $187 \pm 37.64 \mathrm{mmHg}$ and the mean initial diastolic of the intracerebral hemorrhage is $107 \pm 23.2 \mathrm{mmHg}{ }^{4}$ Increased blood pressure is not only increasing the incidence of hemorrhagic stroke but also infarction stroke. ${ }^{5}$ Furthermore, blood pressure is one of the strong predictors of the mortality rate. High blood pressure causes neurological deterioration, and especially in intracerebral hemorrhage cases, the deterioration is deadly. ${ }^{6}$ High blood pressure also increases the chance of increasing the size of hematoma. This might happen because high blood pressure will promote the process of the 'wear and tear' of the blood vessels and it will cause bleeding that happens repeatedly. ${ }^{2}$

Glasgow Coma Scale score has a significant correlation with the 30-day mortality of the patients. The larger the volume of hematoma and the lower the Glasgow Coma scale score is, the higher the risk of the patient to dying during 
hospitalization ${ }^{7,8}$ In Asian, a low initial Glasgow coma scale and a high volume of bleeding are independent factors of bad prognosis. ${ }^{9,10}$ The higher the volume of bleeding in the patient, the risk of the patient to have abad outcome, or in this case, death, is higher. ${ }^{11}$ This statement confirms our study where the volume of bleeding shows a significant correlation with the outcome of the patient. Side, the volume of bleeding, the Glasgow Coma Scale score, intracerebralhemorrhage score, and hematoma shape are all significantly affecting the 30-day mortality rate of the patients. ${ }^{7}$ Low Glasgow Coma Scale score can occur when there is a massive volume of bleeding because of the intracranial pressure or direct compression to the pons or thalamus. ${ }^{12,13}$

The limitation of the study is that complete medical records retrieved are not in sufficient numbers. The bigger data set is needed to represent the reliability of the result, therefore, further study collecting more data is preferable.

To conclude, bleeding volume and consciousness level as determined by the Glasgow Coma Scale score show a significant correlations with the mortality rate in patients with intracerebral hemorrhage. Further follow up study is of great interest in exploring the quality of life of the patients with intracerebral hemorrhage.

\section{References}

1. Badan Penelitian dan Pengembangan Kesehatan Kementerian Kesehatan Republik Indonesia. Riset Kesehatan Dasar 2013. Jakarta: Badan Penelitian dan Pengembangan Kesehatan Kementerian Kesehatan Republik Indonesia; 2013.

2. Aguilar MI, BrottTG.Update in intracerebral hemorrhage.Neurohospitalist. 2011;1(3): 148-59.

3. Macellari F, Paciaroni M, Agnelli G, Caso V. Neuroimaging in intracerebral hemorrhage. Stroke. 2014;45(3):903-8.

4. Yousuf RM, Fauzi ARM, Jamalludin AR, How SH, Amran M, Shahrin TCA, et al. Predictors of in-hospital mortality in primary intracerebral hemorrhage in East coast of Peninsular Malaysia. Neurology Asia. 2012;17(2):93-9.

5. Zia E, Hedblad B, Pessah-Rasmussen H, Berglund G, Janzon L, Engström G. Blood pressure in relation to the incidence of cerebral infarction and intracerebral hemorrhage. Hypertensive hemorrhage: debated nomenclature is still relevant. Stroke. 2007;38(10):2681-5.

6. Willmot M, Leonardi-Bee J, Bath PMW. High blood pressure in acute stroke and subsequent outcome a systematic review. Hypertension. 2004;43(1):18-24.

7. Wang CW, Liu YJ, Lee YH, Hueng DY, Fan HC, Yang FC, et al. Hematoma shape, hematoma size, glasgow coma scale score and ich score: Which predicts the 30-day mortality better for intracerebral hematoma? PLoS One. 2014;9(7):e102326.

8. Broderick JP, Diringer MN, Hill MD, Brun NC, Mayer SA, Steiner T, et al. Determinants of intracerebral hemorrhage growth: An exploratory analysis. Stroke. 2007; 38(3):1072-5.

9. Poungvarin N, Suwanwela NC, Niphon Poungvarin, Venketasubramanian N, Wong LKS, Navarro JC, et al. Grave prognosis on spontaneous intracerebral hemorrhage: GP on STAGE score. J Med Assoc Thail. 2006;89(Suppl 5):S84-93.

10. Chen HS, Hsieh CF, Chau TT, Yang CD, Chen YW. Risk factors of in-hospital mortality of intracerebral hemorrhage and comparison of ICH scores in a Taiwanese population. Eur Neurol. 2011;66(1):59-63.

11. Suthar NN, Patel KL, Saparia C, Parikh AP. Study of clinical and radiological profile and outcome in patients of intracranial hemorrhage. Ann Afr Med. 2016;15(2):6977.

12. Qureshi AI, Tuhrim S, Broderick JP, Batjer $\mathrm{HH}$, Hondo H, Hanley DF. Spontaneous intracerebral hemorrhage. $\mathrm{N}$ Engl J Med. 2001;344(19):1450-60.

13. Salihović D, Smajlović D, Ibrahimagić OĆ. Does the volume and localization of intracerebral hematoma affect short-term prognosis of patients with intracerebral hemorrhage?. ISRN Neurosci. 2013;2013: 327968. 